\title{
Full mouth rehabilitation of Kennedy class 1 edentulous situation complicated with excessive deep bite: an interdisciplinary approach
}

\author{
Bhushan Kumar $^{1 *}$, A. Navin Kumar², Prabhdeep Kaur Sandhu ${ }^{3}$
}

\author{
${ }^{1}$ Department of Prosthodontics, ${ }^{2}$ Department of OMFS, Army Dental Corps, Ambala Cantt, Haryana, India \\ ${ }^{3}$ MDS (Orthodontics), Private Consultant, Ambala Cantt, Haryana, India
}

Received: 01 October 2018

Accepted: 20 October 2018

\section{*Correspondence:}

Dr. Bhushan Kumar,

E-mail: drbhushansheoranmds@gmail.com

Copyright: (C) the author(s), publisher and licensee Medip Academy. This is an open-access article distributed under the terms of the Creative Commons Attribution Non-Commercial License, which permits unrestricted non-commercial use, distribution, and reproduction in any medium, provided the original work is properly cited.

\begin{abstract}
Oral rehabilitation of bilateral mandibular edentulous posterior segments becomes even more difficult if patient had severe deep bite in natural dentition. This case report demonstrates the intelligent way of managing severe deep-bite by adapting multi-disciplinary approach. Involved steps are: Mandibular subapical osteotomy of mandibular anterior segment to lower down the fragment; secondly, the maxillary anteriors were done with crown lengthening followed by decreased incisal display and thirdly by restoring vertical dimension of occlusion by replacement of missing posterior teeth. The addition of surgical intervention (anterior mandibular osteotomy) in the present case has found to be effective and quick adjunctive in achieving functional improvement in occlusion by reducing anterior teeth overlap (deep bite), by decreasing incisal guidance steepness and esthetic display of anterior teeth. Bilateral edentulous situation was managed by precision attachment retained cast partial denture. A satisfactory functional and esthetic result was obtained.
\end{abstract}

Keywords: Anterior mandibular segmental osteotomy, Class II deep-bite, Kennedy class 1 edentulism, Crown lengthening

\section{INTRODUCTION}

Deep bite cases pose a challenge both for the clinician and patient. Skeletal deep bite cannot be treated alone by fixed orthodontic therapy. For such cases inclusion of orthognathic surgical procedures in treatment plan is more viable option. ${ }^{1}$ Anterior segmental mandibular osteotomy is a surgical procedure employed to separate the mandibular anterior dento-alveolar segment from the basal bone. This procedure gives flexibility to manipulate the fractured segment in any of the plane to correct deformity like lowering down the segment by removing basal bone at fracture line to reduce deep bite extent, displacement of the fractured segment lingually or buccally for correction of prognathism/retrognathism or by changing the inclination of dentoalveolar segment to correct the incisal guidance. ${ }^{1-4}$

\section{CASE REPORT}

A 45-year-old female patient had reported to dental department with a chief complaint of difficulty while having meals and also an unattractive smile. The patient had no systemic medical complaints and no other muscular hyperactivity or temporomandibular dysfunctions were observed. Extraoral examination showed gummy smile in upper anterior teeth, (Figure 1a) reduction in the lower facial height due to overclosure. Intra-oral periodontal examination showed no pocket depth of over $2 \mathrm{~mm}$ or mobility of the remaining teeth.

The intraoral and radiographic examination verified that $22,26,34,36,37,45,46,47$ were missing. Patient had interdental restorations in maxillary anterior teeth (Figure $1 \mathrm{~b}$ and c) She also had severe deep-bite of around $16 \mathrm{~mm}$ 
(incisal edges of upper anteriors were overlapping $6 \mathrm{~mm}$ beyond mandibular gingival margins) (Figure $1 \mathrm{~b}$ ) Maxillary incisors were showing excessive visibility, slightly retroclined with only $1 \mathrm{~mm}$ of overjet. The mandibular posterior teeth were absent and mandibular premolars were not touching opponents, so there was loss of VDO and this was the main reason behind such excessive deep bite. Some attrition was also noticed on mandibular incisors (Figure $1 \mathrm{~d}$ ).
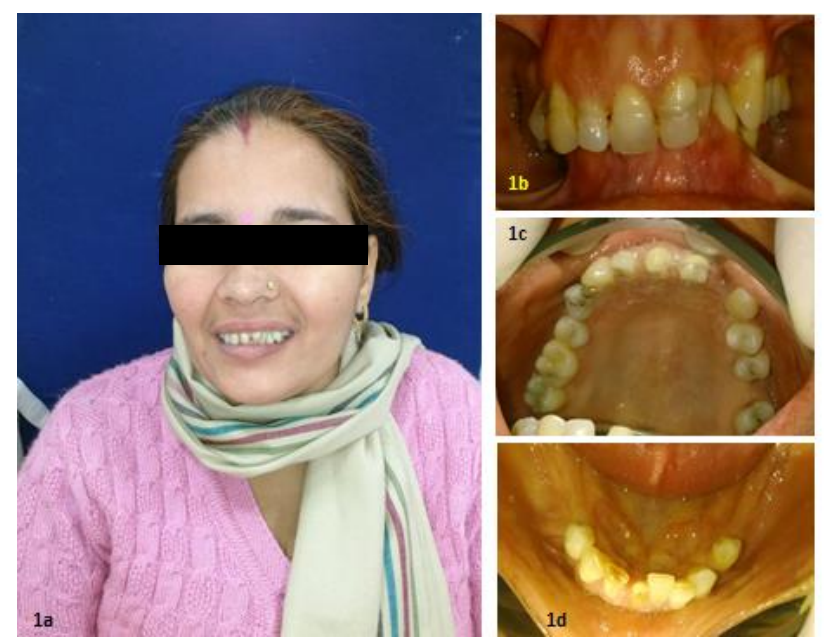

Figure 1 (a-d): Pre-oprative extra-oral view and intraoral view.

Firstly, the diagnostic casts were mounted using interocclusal record at corrected vertical dimension of occlusion (VDO) on a semi-adjustable articulator after face-bow transfer.

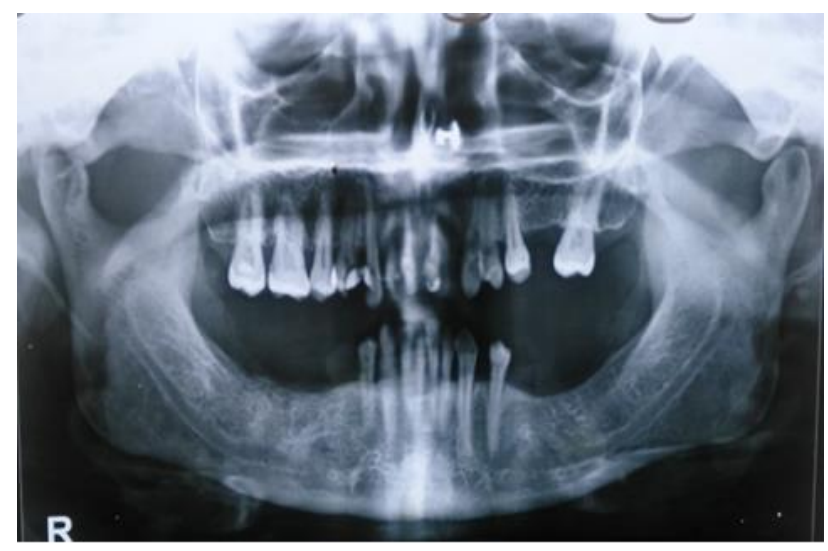

Figure 2: Pre-operative radiographic view (OPG).

With all records and findings, the case was discussed among orthodontist, oral-maxillofacial surgeon, prosthodontist and periodontist to formulate a treatment plan. Orthodontist denied for the option of fixed orthodontics for correction of deep bite as there was no posterior anchorage in mandibular arch. Oral and maxillofacial surgeon, after evaluating OPG (Figure 2) and patient clinically, expressed the feasibility of $4 \mathrm{~mm}$ correction in deep bite by downward displacement of mandibular anterior segment using subapical osteotomy. Periodontist advised for correction of gummy smile by crown lengthening procedure and by doing so prosthodontist got an advantage of giving artificial maxillary crowns more apically. This had solved two purposes. One was restoration of esthetics smile and second was the scope of reduction in deep bite by $3 \mathrm{~mm}$. Dental implants were considered for replacement of missing teeth but due to financial aspect patient rejected this option. Prosthodontist advised removable cast partial dentures with incorporated precision attachments for the same.

Treatment plan was explained to the patient and after taking consent the procedures were performed in phased manner.

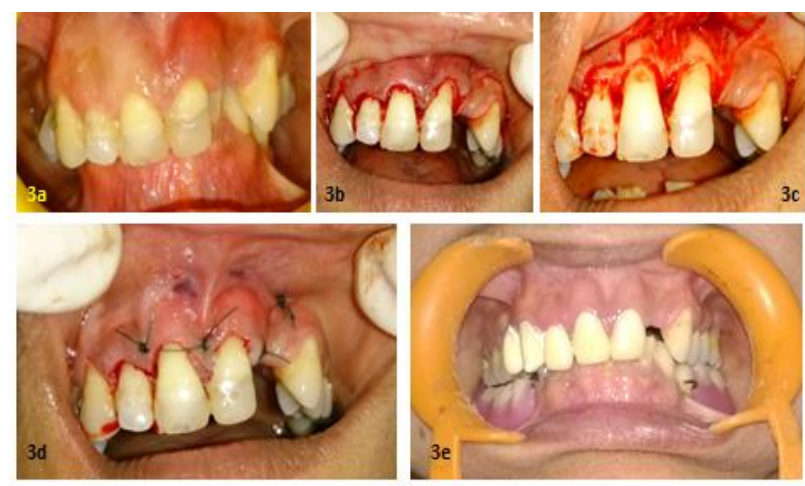

Figure 3 (a-c): are steps in crown lengthening procedure, (d) provision crowns to retore crown height of maxillary anteriors.

\section{Phase 1: Pre-Surgical}

- Restorations were done for required teeth $(17,25$, 27).

- $\quad$ RCT were performed on maxillary $(11,12,13,14$, $21)$ and mandibular teeth $(31,32,33,35,41,42,43$, 44).

- Patient education and motivation for oral hygiene maintenance.

\section{Phase 2: Periodontal correction of gummy smile}

- Crown lengthening with $2 \mathrm{~mm}$ of alveoloplasty was performed on 11, 12, 21 (Figure 3a-c).

\section{Phase 3: Correction of incisal length of maxillary anterior teeth}

- After crown lengthening procedure clinical crown height had increased by $2 \mathrm{~mm}$ and to compensate this provisional crown were given with more apical extension. Incisally, $3 \mathrm{~mm}$ reduction was achieved when compared to previous incisal edge position (Figure 3d).

- An interim RPD was given at this stage to establish VDO. 


\section{Phase 4: Surgical phase}

- Mandibular anterior Subapical Osteotomy was performed under General Anaesthesia. A reduction of $4 \mathrm{~mm}$ of basal bone at split area allowed the surgeon to reposition the segment inferiorly. This resulted in reduction of $4 \mathrm{~mm}$ in deep bite (Figure 4 ).

- Fractured segment then fixed with adjacent mandible using bone plate and screws.
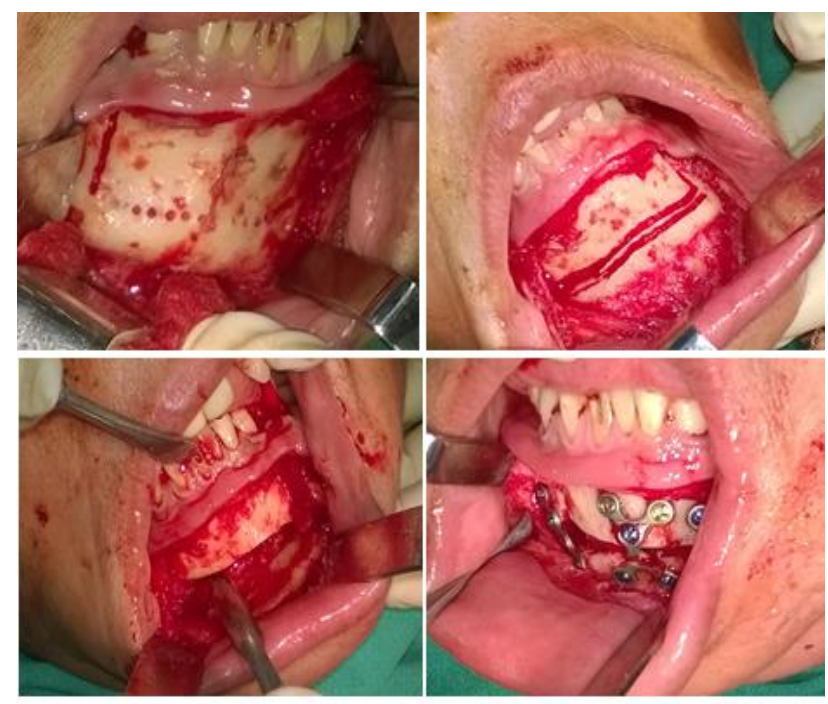

Figure 4: Mandibular anterior subapical osteotomy procedure.

\section{Phase 5: Prosthetic phase}

- Objectives were to establish an incisal guidance harmonious to condylar guidance and restoration of missing teeth.

- Crown preparations were done for PFM (Figure 5).

- Design included: separate crowns for 12, 13 and 14; joined crowns of 11,21 with 22 as cantilever. A three unit PFM bridge over 25 and 27 with 26 as pontic. Again a three unit bridge was planned over 33 and 35 replacing 34 as pontic. Prefabricated Doldar Bar was incorporated in wax pattern distal to 35 for incorporation of Bar and Clip precision attachment for retention in removable cast partial denture. 31,32 were joined together as root length was less, similarly 41 and 42 were also joined. 43 and 44 were joined and incorporated with Doldar Bar distal to 44 with the same goal of providing retention to removable cast partial denture.

- All PFM FPD were then cemented using GIC luting cement (Figure 6). Height of mandibular anterior teeth was less, compared to pre-operative natural teeth and it gave a reduction of deep bite by $2 \mathrm{~mm}$, so final treatment outcome was $2 \mathrm{~mm}$ overjet and $2 \mathrm{~mm}$ overbite.

- A cast partial denture was fabricated using ceramic teeth (Figure 7a).
- Nylon clips with metal housings were incorporated bilaterally corresponding to their Doldar Bar using indirect method (Figure 7b).

- Prosthesis was checked for occlusion. Group function occlusion was established (Figure 8).

- Patient was given with all necessary instructions for do's or don'ts and oral hygiene maintenance.
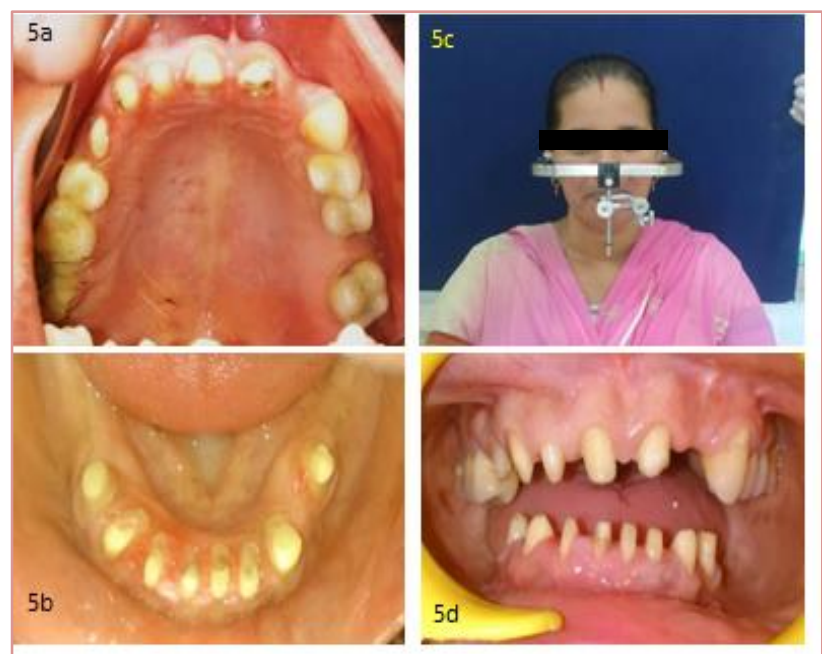

Figure 5 (a-d): Crown preparations.

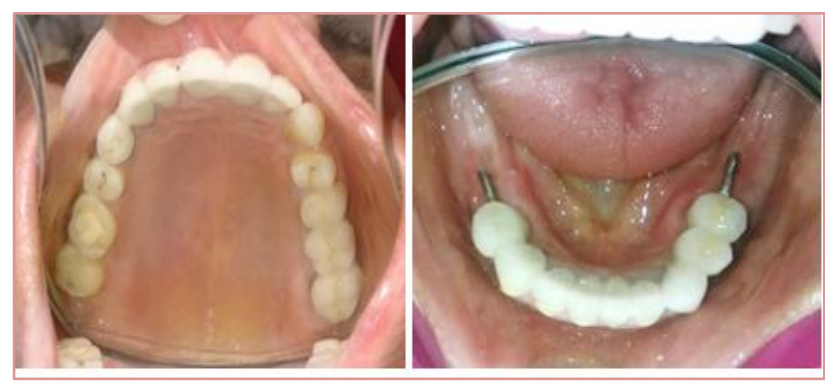

Figure 6: Final PFM prosthesis cemented in mouth.

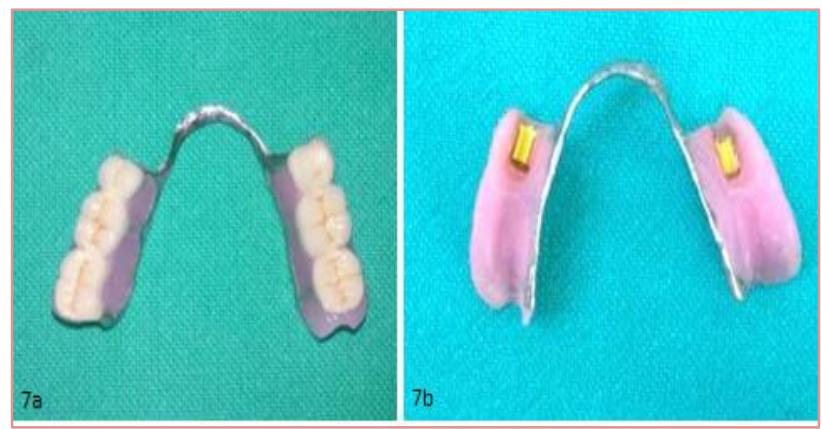

Figure 7 (a and b): Cast partial denture occlusal and intaglio surface view.

\section{Phase 6: Follow up phase}

- Patient was recalled on weekly basis for the first one month for clinical evaluation. 


\section{Treatment outcome}

$14 \mathrm{~mm}$ of deep bite was managed, functional occlusion achieved and patient was happy with the smile esthetics (Figure 9).

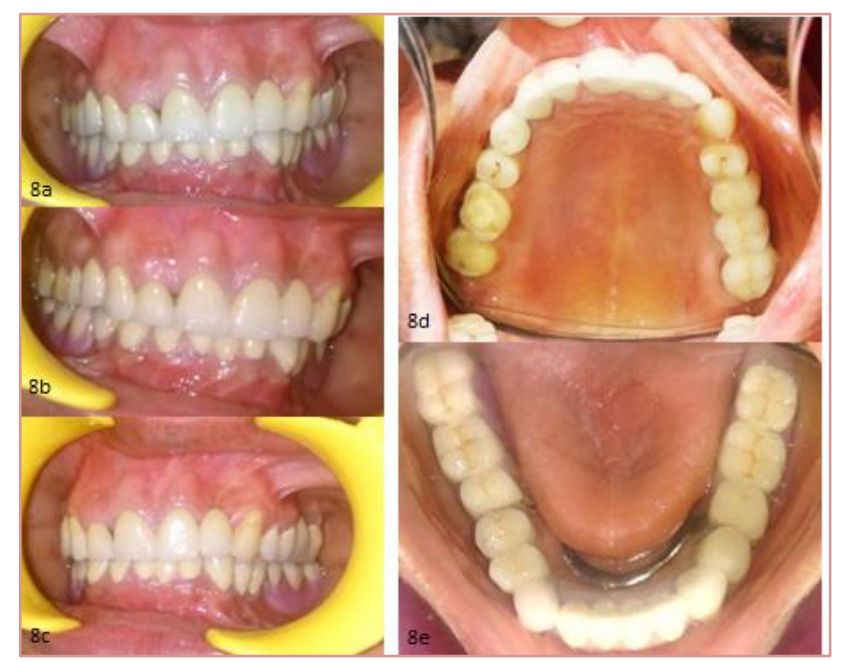

Figure 8: Post operative intra-oral view.

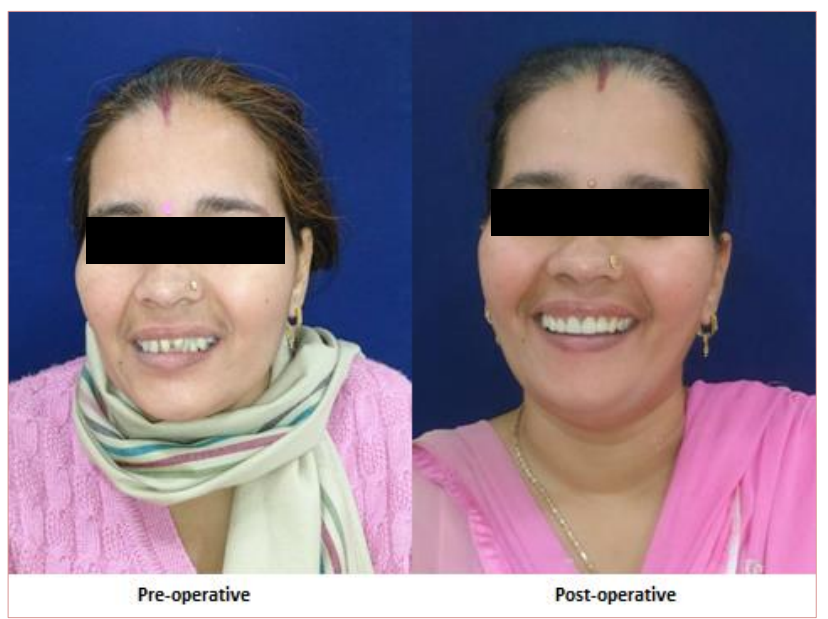

Figure 9: Pre and post-operative extra-oral view.

\section{DISCUSSION}

Treatment goals in the present case were to improve esthetics, to reduce deep bite, to restore all missing teeth and establishing the incisal guidance harmonious with condylar guidance.

Normal crown lengthening procedure for maxillary anterior teeth followed by prosthetic replacement of original height more apically was sufficient in achieving the first goal of esthetic smile.

Second goal of management of excessive deep bite of $16 \mathrm{~mm}$ was a herculean task which was managed through a synchronized inter-disciplinary approach and formulation of meticulous treatment planning. $5 \mathrm{~mm}$ vertical height was managed by restoring VDO, $4 \mathrm{~mm}$ by downward positing of mandibular anterior segment through subapical osteotomy, $3 \mathrm{~mm}$ during restoration of normal crown height for maxillary anterior teeth after crown lengthening procedure and final $2 \mathrm{~mm}$ of reduction was by reducing crown height of mandibular anterior teeth during prosthetic rehabilitation process.

Mandibular segmental subapical osteotomy procedure was first described by Hullihen ${ }^{5}$ to correct dento-skeletal malocclusion which otherwise are difficult to be dealt with orthodontic treatment. These dental-alveolar changes are performed by altering position or inclination of fractured segment in an axial, antero-posterior, transverse and vertical direction within physiologic limits to achieve desired results. ${ }^{1-6}$

The precision attachments are not new but their use is uncommon because of lack in their awareness among the dental professionals and less availability of these attachments in market. A removable prosthesis with attachment is an efficient and cost-effective treatment option for long span distal extension edentulous ridge. Their advantages include excellent retention of removable prosthesis, ease of maintaining cleanliness below artificial teeth when compared to FPD, cost effective, elimination of clasp assembly gives more esthetic result etc. $^{7-9}$

Vertical dimension of occlusion (VDO) is also an important aspect to carefully monitor. It should be restored not increased. Any variation from physiologic values can lead to TMJ problems, muscle pain etc. ${ }^{10}$

\section{CONCLUSION}

The present case demonstrate the multidisciplinary approach in management of excessive deep bite using various approaches simultaneously in same case to achieve esthetic and functional treatment outcome. Careful diagnosis and meticulous treatment planning is very much required for reaching a goal of full mouth rehabilitation.

Funding: No funding sources Conflict of interest: None declared

Ethical approval: Not required

\section{REFERENCES}

1. Boye T, Doyle P, McKeown F, Sandler J. Total subapical mandibular osteotomy to correct class 2 division 1 dento-facial deformity. J Cranio maxillofac Surg. 2012;40(3):238-42.

2. Ergun G, Yucel AS. Full-mouth rehabilitation of a patient with severe deep bite: A clinical report. J Prosthodont. 2014;23:406-11.

3. Eliades T, Hegdvedt AK. Orthodontic-surgical correction of a Class II, Division 2 malocclusion. 
Am J Orthod Dentofacial Orthop. 1996;110(4):3517.

4. Ergun G, Bozkaya E. Full-mouth rehabilitation of Class II deep-bite patient: A 5-year clinical report. Eur J Dent. 2016;10(3):426-31.

5. Ali RM, Schache A, Walsh S, Sneddon K. Total mandibular subapical osteotomy: modification of the technique. $\mathrm{Br} \mathrm{J}$ Oral Maxillofac Surg. 2009;46(7):629-30.

6. Park JU, Hwang YS. Evaluation of the soft and hard tissue changes after anterior segmental osteotomy of the maxilla and mandible. J Oral Maxillofac Surg. 2008;66(1):98-103.

7. Windchy AM, Morris JC. An alternative treatment with the overlay removable partial denture: A clinical report. J Prosthet Dent. 1998;79:249-53.

8. Asvanund C, Morgano SM. Restoration of unfavorably positioned implants for a partially endentulous patient by using an overdenture retained with a milled bar and attachments: A clinical report. J Prosthet Dent. 2004;91:6-10.

9. Davodi A, Nishimura R, Beumer J. An implantsupported fixed-removable prosthesis with a milled tissue bar and Hader clip retention as a restorative option for the edentulous maxilla. J Prosthet Dent.1997;78:212-7.

10. Abduo J, Lyons K. Clinical considerations for increasing occlusal vertical dimension: A review. Aust Dent J. 2012;57:2-10.

Cite this article as: Kumar B, Kumar AN, Sandhu PK. Full mouth rehabilitation of Kennedy class 1 edentulous situation complicated with excessive deep bite: an interdisciplinary approach. Int J Otorhinolaryngol Head Neck Surg 2018;4:1493-7. 